\title{
Spiritual Well-Being and Quality of Life of Iranian Adults with Type 2 Diabetes
}

\author{
Najmeh Jafari, ${ }^{1,2}$ Ziba Farajzadegan, ${ }^{2}$ Amir Loghmani, ${ }^{2}$ \\ Mansoureh Majlesi, ${ }^{3}$ and Noushin Jafari ${ }^{4}$ \\ ${ }^{1}$ George Washington Institute for Spirituality and Health, School of Medicine and Health Sciences, George \\ Washington University, Washington, DC 20036, USA \\ ${ }^{2}$ Community Medicine Department, School of Medicine, Isfahan University of Medical Sciences, \\ Isfahan 81745-313, Iran \\ ${ }^{3}$ Vice-Chancellery for Treatment, Isfahan University of Medical Sciences (IUMS), Isfahan 81656-47194, Iran \\ ${ }^{4}$ Anesthesiology Department, School of Medicine, Isfahan University of Medical Sciences, \\ Isfahan 81745-313, Iran
}

Correspondence should be addressed to Amir Loghmani; a_loghmani@resident.mui.ac.ir

Received 6 June 2013; Revised 25 November 2013; Accepted 28 November 2013; Published 29 January 2014

Academic Editor: Klaus Baumann

Copyright (C) 2014 Najmeh Jafari et al. This is an open access article distributed under the Creative Commons Attribution License, which permits unrestricted use, distribution, and reproduction in any medium, provided the original work is properly cited.

\begin{abstract}
Introduction. Diabetes is a major public health problem. Little is known about the spiritual well-being and its relationship with quality of life (QOL) in Iranian Muslim patients with diabetes. This study investigated the spiritual well-being and QOL of Iranian adults with type 2 diabetes and the association between spiritual well-being, QOL, and depression. Methods. A cross-sectional study was done among 203 patients with type 2 diabetes mellitus in Isfahan, Iran. Quality of life and spiritual well-being were measured using the functional assessment of chronic illness therapy-spiritual well-being (FACIT-Sp). Depression was assessed using the Patient Health Questionnaire-2 (PHQ-2). Descriptive analysis, Pearson's correlation, and multiple regression analysis were performed for statistical assessment. Results. The mean QOL was $61.00(\mathrm{SD}=9.97)$ and the mean spiritual well-being was 30.59 ( $S D=6.14)$. Sixty-four percent of our studied population had depressive disorders. There was a significant positive correlation between all QOL subscales and meaning, peace, and total spiritual well-being score. Conclusion. The results of this study showed poor QOL and spiritual well-being and high prevalence of depression in Iranian patients with type 2 diabetes compared to other studies' findings especially western studies. This indicates the need for psychosocial and spiritual support in caring for Iranian patients with diabetes.
\end{abstract}

\section{Introduction}

Diabetes is a serious public health problem with an increasing incidence in Middle East countries as well as Iran [1]. Five of the 10 world's highest national prevalences of diabetes occur in Middle East countries, that might be expected to increase in the coming decades $[1,2]$. The last nationally representative report of the burden of diabetes in Iran showed a high prevalence of diabetes $(8.7 \%)$ in Iranian population, which is estimated to rise to $9.8 \%$ in upcoming decades [3].

Diabetes is one of the most psychologically demanding chronic medical disorders and is often associated with several psychiatric disorders [4]. Diabetic patients are about twice as likely as people without the condition to have anxiety, depression, and serious psychological problems [5-7]. Emotional distress may influence outcomes in terms of glycemic control, adherence to medical treatment, cost of care, and mortality [8].

The interface between poor physical health and poor mental health affects quality of life (QOL) of diabetic patients [9]. QOL is a broad, multifaceted concept [10]. It incorporates the individual's subjective perception of physical, emotional, cognitive, social, and spiritual domains of an individual's life [11]. Several studies indicated that diabetic patients have 
reduced QOL compared to general population in the same age group $[12,13]$, and their QOL decreases with diseased progression and complications $[14,15]$.

Among several components of QOL, spirituality receives more attention in recent years [16]. Spirituality is defined as "the aspect of humanity that refers to the way individuals seek and express meaning and purpose and the way they experience their connectedness to the moment, to self, to others, to nature, and to the significant or sacred" [17]. There is a strong association between spirituality and coping with chronic medical disease [18], willingness to live [19], reducing anxiety and depression [20], and improving quality of life [21].

The importance of addressing spirituality in diabetes management is indicated in several studies. Previous studies on African American population showed that there is a positive relationship between spiritual well-being and coping with diabetes, glycemic control, and self-management. [2224]. However, there is minimal information regarding the spirituality of patients of different cultures such as Iranian Muslim patients.

In two qualitative studies from Iran, the role of spiritual beliefs in coping with diabetes and patients' empowerment is indicated $[25,26]$. However, there is still lack of evidence regarding measuring the spiritual well-being and assessing its association with QOL using a standard tool. Different cultural groups and religious affiliations may emphasize different aspects of their QOL and spiritual well-being [27]. Assessing the local perspectives by international instruments will provide an opportunity for cross-cultural comparisons and developing the best interventions based on the needs of patient with diabetes.

The aims of this study were to describe the spiritual well-being and QOL of Iranian adults with type 2 diabetes and to investigate the association between spiritual wellbeing, QOL, and depression among Iranian adults with type 2 diabetes.

\section{Materials and Methods}

This was a cross-sectional study, which was conducted in two diabetes care institutes in Isfahan, Iran, from January 2013 to April 2013. These institutes are main diabetes care centers located in two different geographic areas of Isfahan city, covering more than 10,000 diabetes patients with diverse socioeconomic characteristics. The target population was patients with type 2 diabetes who had registered in these institutes and consented to participate. People aged 18 or above with a definitive diagnosis of type 2 diabetes, as confirmed by a physician, with or without complication and the ability to read and write Farsi, were enrolled in the study. The exclusion criteria was any documented diagnosis of end-stage renal disease, psychotic disorder, dementia, or blindness.

2.1. Instruments. To assess the spiritual well-being and QOL of participants, we used the functional assessment of chronic illness therapy-spiritual well-Being (FACIT-Sp) scale. This is a valid and reliable instrument that was developed in the 1990s to provide an inclusive measure of spirituality in research and clinical practice [28, 29]. This questionnaire assesses spirituality well-being as well as QOL regardless of religious or spiritual tradition [29]. It consists of a core general questionnaire for measuring QOL and an additional scale for measuring spirituality. The core general questionnaire that measures QOL (FACT-G) is composed of four subscales: physical well-being ( $\mathrm{PWB}=7$ items), social/family well-being (SWB $=7$-items), emotional wellbeing $(\mathrm{EWB}=6$ items $)$, and functional well-being (FWB $=7$ items) [30]. The additional scale for measuring spirituality contains 12 items and three subdomains (peace, meaning, and faith) [29]. The FACIT-Sp is self-administered and uses a 5-point Likert-type scale $(0=$ not at all; $4=$ very much) and the score range of 0-48 [29]. The higher score represents the better spiritual well-being. All three scales have high internal consistency (Cronbach's alpha for total scale 0.87 , for meaning/peace subscale 0.81 , for faith subscale 0.88 ). This questionnaire is translated and validated to Persian by authors and we found that the Persian version of the FACIT-Sp scale is a reliable and valid tool for the clinical assessment of, and research into, the spiritual well-being of Muslim Iranians [31].

We evaluated depression using the 2-item patient health questionnaire depression module, the PHQ-2 [32]. This tool inquires about the frequency of depressed mood and anhedonia over the past 2 weeks, scoring each as 0 (not at all) to 3 (nearly every day); thus, the PHQ-2 score can range from 0 to 6 . PHQ-2 cutoff score of $\geq 3$ had the best tradeoff between sensitivity (79\%) and specificity (86\%) for any depressive disorder. This tool appears promising as a brief sensitive and specific tool for detecting and monitoring of depression [33].

To assess the glycemic control of participants we consider glycosylated hemoglobin $\mathrm{HbA}_{1 \mathrm{c}}$ as a reliable index of longterm glycemic control in patients with diabetes. An elevated $\mathrm{HbA}_{1 \mathrm{c}}$ indicates poor long-term glycemic control [34]. In this study $\mathrm{HbA}_{1 \mathrm{c}}$ level $\leq 7$ was considered as controlled diabetes and $\mathrm{HbA}_{1 \mathrm{c}}$ level $>7$ as uncontrolled diabetes.

Patients were randomly sampled using IBM SPSS Statistics for Microsoft Windows, Version 21. Demographic information (age, marital status, education, and occupation) was collected through a self-administered questionnaire. Clinical data including laboratory and concurrent chronic disease were extracted from medical records. After oral and written consent, participants were instructed to read the brief directions at the top of the questionnaire. After confirming the participants' correct understanding, they were encouraged to complete every item in private. A total of 203 participants completed the FACIT-Sp, PHQ-2, and demographic information questionnaire.

2.2. Statistical Analysis. The sample was described using means and standard deviations for quantitative variables and relative frequencies and percentages for categorical variables. $t$-test analysis was used to compare the mean of FACIT-Sp and PHQ-2 scores in two groups (controlled diabetes and uncontrolled group). 
The bivariate relationship between spiritual well-being, QOL subscales, depression, and diabetes control $\left(\mathrm{HbA}_{1 \mathrm{c}}\right)$ was assessed by calculating Pearson correlation coefficients. Variables were selected for inclusion in the multiple regression model based on theoretical importance as well as significance in bivariate analyses. Multiple regression analysis was used to assess the predictor role of the 12-item spiritual well-being subscale of the FACIT-Sp subdomains (peace, meaning, and Faith) on determinants of QOL. The FACT-G total scores and its subdomains (PWB, SWB, EWB, and FWB) considered as the dependent variables [35] and the independent (predictor) variables (peace, meaning, and faith, PHQ-2 and $\mathrm{HbA}_{1 \mathrm{c}}$ ) were entered in blocks.

Collinearity diagnostics were performed by means of the variance inflation factor (VIF) for each independent variable entered in the regression equations. A VIF $>10$ was considered as positive multicollinearity [36]. The level of significance was set at $P>0.05$, and all tests were two-tailed. Data were analyzed using SPSS (version 21) for Windows.

\section{Results}

Over a six-week-period, 223 patients met the inclusion criteria and were recruited. Twenty patients were excluded because of dementia $(n=6)$, psychotic disorders $(n=3)$, and declining to take part $(n=11)$. The mean age of all participants was $55.42(\mathrm{SD}=10.67)$ with a range of $18-87$ years. The majority of participants were female $(69.5 \%)$ and married (95.1\%). Seventy-two percent of participants were housewives and $8.4 \%$ were retired. Seventy-six percent of them were educated below high school diploma, 29 patients received their diploma, and 18 patients had master degree from the university. No gender differences were detected regarding education. All patients identified themselves as Muslim. There was no statistically significant difference regarding demographic characteristics between patients who participated and who declined $(P>0.05)$.

The mean of fasting blood sugar (FBS) was 163.26 (SD = 62.14). Among our participants, 76 diabetic patients $(37.4 \%)$ were in the controlled group $\left(\mathrm{HbA}_{1 \mathrm{c}} \leq 7\right)$ and $127(63 \%)$ were in uncontrolled group $\left(\mathrm{HbA}_{1 \mathrm{c}}>7\right)$.

The mean score of FACT-G was $61.00(\mathrm{SD}=9.97)$. The mean spiritual well-being (FACIT-Sp12) score was 30.59 out of 48 ( $\mathrm{SD}=6.14)$ with the highest mean score in the faith subscale (mean $=10.78, \mathrm{SD}=2.89$ ) in comparison to the other subscales. The mean PHQ-2 score was 4.7 (S.D. $=1.5)$. Considering the cutoff score of $\geq 3,63.5 \%$ of our studied population had depressive disorders.

In one-way ANOVA, there was no statistically significant difference in QOL, spiritual well-being, and depression scales regarding demographic status $(P>0.05)$. Among FACITSp subdomains, the mean of physical well-being, emotional well-being, functional well-being, and peace scores was higher in controlled diabetes group in comparison to uncontrolled group $(P<0.05)$. People in uncontrolled group had higher score in PHQ-2 score of depression $(P=0.047)$. Table 1 shows participants' quality of life as well as spiritual well-being and depression scores in two groups.
Table 2 lists the bivariate Pearson correlation coefficients between the QOL, spirituality, and depression measures. There was a statistically significant positive correlation between all QOL subscales (physical, social, emotional, and functional well-being) and meaning, peace, and total FACITSp-12 scores. $\mathrm{HbA}_{1 \mathrm{c}}$ was negatively associated with physical well-being, emotional well-being, functional well-being, and peace, otherwise, positively correlated with depression. Depression was also significantly correlated with all QOL and spiritual well-being subscales and this association was highest with emotional well-being $(r=-0.56, P<0.001)$, physical well-being $(r=-0.52, P<0.001)$, and peace $(r=-0.48$, $P<0.001)$.

In regression analyses, after evaluating the correlations among the independent variables, no multicollinearity problem was detected. Meaning and peace subscales of FACITSp12 were significantly associated $(P<0.05)$ with total QOL. Meaning, peace, faith, and depression were significantly associated with physical well-being $\left(R^{2}=0.37, P<\right.$ $0.005)$. In each of these analyses, the meaning and peace subscales were significantly associated with the subdomains of QOL. The faith subscale, on the other hand, was only associated with physical well-being and did not provide an independent contribution to prediction of other domains. Furthermore, $\mathrm{HbA}_{1 \mathrm{c}}$ did not contribute significantly to any of these outcomes (Table 3 ).

\section{Discussion}

This study was designed to assess spiritual well-being and QOL together with depression in a population of Iranian people with type 2 diabetes and to explore their possible associations. Our studied population had poor spiritual wellbeing and quality of life in comparison to the normative data of the general U.S. population [37] but similar to another study from Iran in patients with cancer [31].

In our Muslim population, the highest score of spiritual well-being was related to faith subdomain of FACIT-Sp12. This coheres with other studies in Muslim population [38, 39]. The "faith" component of FACIT-Sp-12 is most often associated with religion and religious beliefs [40], but spirituality extends beyond religion and is independent of commitment to a particular religion or doctrine [41]. Spirituality is experiencing transcendent meaning and purpose in life as well as sense of connectedness. Several studies indicated the importance of spirituality in coping with disease, better QOL, and hopefulness [42-45]. In our study meaning and peace subscales of FACIT-Sp12 were significantly associated with all aspects of QOL. In regression analyses, higher meaning and peace were related to better physical, social, emotional, and functional well-being as well as total QOL, whereas higher faith was only associated with physical well-being. These results are consistent with our study on Iranian patients with breast cancer, which showed that meaning and peace are more robust indicators of QOL than faith. This may be due to negative religious coping (e.g., belief that one's illness is God's punishment or abandonment) in patients with chronic illnesses [46]. However, this result is not specific to Iranian 
TABLE 1: FACT-G, FACIT-Sp12, and PHQ-2 scores of two groups (controlled and uncontrolled diabetic patients).

\begin{tabular}{|c|c|c|c|c|}
\hline Domains & Group & Mean & Std. deviation & $P$ value \\
\hline \multirow{2}{*}{ Physical well-being } & Controlled & 17.61 & 6.18 & \multirow{2}{*}{0.033} \\
\hline & Uncontrolled & 15.73 & 5.99 & \\
\hline \multirow{2}{*}{ Social/family well-being } & Controlled & 16.39 & 5.18 & \multirow{2}{*}{0.482} \\
\hline & Uncontrolled & 15.84 & 5.52 & \\
\hline \multirow{2}{*}{ Emotional well-being } & Controlled & 10.80 & 5.38 & \multirow{2}{*}{0.045} \\
\hline & Uncontrolled & 9.27 & 5.09 & \\
\hline \multirow{2}{*}{ Functional well-being } & Controlled & 19.55 & 4.24 & \multirow{2}{*}{0.004} \\
\hline & Uncontrolled & 17.52 & 5.01 & \\
\hline \multirow{2}{*}{ Meaning } & Controlled & 10.97 & 3.11 & \multirow{2}{*}{0.214} \\
\hline & Uncontrolled & 10.44 & 2.76 & \\
\hline \multirow{2}{*}{ Peace } & Controlled & 10.30 & 2.49 & \multirow{2}{*}{$<0.001$} \\
\hline & Uncontrolled & 8.46 & 2.68 & \\
\hline \multirow{2}{*}{ Faith } & Controlled & 11.03 & 2.68 & \multirow{2}{*}{0.339} \\
\hline & Uncontrolled & 10.63 & 3.00 & \\
\hline \multirow{2}{*}{ FACIT Sp12-score } & Controlled & 32.31 & 6.34 & \multirow{2}{*}{0.002} \\
\hline & Uncontrolled & 29.55 & 5.79 & \\
\hline \multirow{2}{*}{ FACIT Sp-score } & Controlled & 95.15 & 13.88 & \multirow{2}{*}{0.005} \\
\hline & Uncontrolled & 89.45 & 13.64 & \\
\hline \multirow{2}{*}{ PHQ-2 score } & Controlled & 2.73 & 1.87 & \multirow{2}{*}{0.047} \\
\hline & Uncontrolled & 4.22 & 1.70 & \\
\hline
\end{tabular}

$\mathrm{HbA}_{1 \mathrm{c}}$ level $\leq 7$ : controlled diabetes $(n=76)$.

$\mathrm{HbA}_{1 \mathrm{c}}$ level > 7: uncontrolled diabetes $(n=127)$.

TABLE 2: Pearson's correlation coefficients between FACT-G, FACIT-Sp12, and PHQ-2.

\begin{tabular}{|c|c|c|c|c|c|c|c|c|c|c|}
\hline & $\begin{array}{c}\text { Physical } \\
\text { well-being }\end{array}$ & $\begin{array}{c}\text { Social } \\
\text { well-being }\end{array}$ & $\begin{array}{l}\text { Emotional } \\
\text { well-being }\end{array}$ & $\begin{array}{l}\text { Functional } \\
\text { well-being }\end{array}$ & Peace & Meaning & Faith & $\begin{array}{c}\text { Spiritual } \\
\text { well-being }\end{array}$ & PHQ-2 & $\mathrm{HbA}_{1 \mathrm{c}}$ \\
\hline $\begin{array}{l}\text { Physical } \\
\text { well-being }\end{array}$ & 1 & $0.245^{* *}$ & $0.604^{* *}$ & $0.381^{* *}$ & $0.433^{* *}$ & $0.430^{* *}$ & $0.476^{* *}$ & $0.376^{* *}$ & $-0.522^{* *}$ & $-0.159^{* *}$ \\
\hline $\begin{array}{l}\text { Social } \\
\text { Well-being }\end{array}$ & & 1 & $0.351^{* *}$ & $0.448^{* *}$ & $0.475^{* *}$ & $0.400^{* *}$ & 0.009 & $0.409^{* *}$ & $-0.315^{* *}$ & -0.054 \\
\hline $\begin{array}{l}\text { Emotional } \\
\text { well-being }\end{array}$ & & & 1 & $0.418^{* *}$ & $0.492^{* *}$ & $0.558^{* *}$ & 0.107 & $0.534^{* *}$ & $-0.565^{* *}$ & $-0.141^{*}$ \\
\hline $\begin{array}{l}\text { Functional } \\
\text { well-being }\end{array}$ & & & & 1 & $0.564^{* *}$ & $0.601^{* *}$ & $0.189^{* *}$ & $0.626^{* *}$ & $-0.408^{* *}$ & $-0.153^{*}$ \\
\hline Meaning & & & & & 1 & $0.498^{* *}$ & 0.089 & $0.739^{* *}$ & $-0.460^{* *}$ & -0.002 \\
\hline Peace & & & & & & 1 & $0.237^{* *}$ & $0.797^{* *}$ & $-0.476^{* *}$ & $-0.253^{* *}$ \\
\hline Faith & & & & & & & 1 & $0.619^{* *}$ & $-0.203^{* *}$ & -0.127 \\
\hline $\begin{array}{l}\text { Spiritual } \\
\text { well-being }\end{array}$ & & & & & & & & 1 & $-0.511^{* *}$ & $-0.213^{* *}$ \\
\hline PHQ-2 & & & & & & & & & 1 & $0.230^{* *}$ \\
\hline $\mathrm{HbA}_{\mathrm{lc}}$ & & & & & & & & & & 1 \\
\hline
\end{tabular}

${ }^{* *}$ Correlation is significant at the 0.05 level (2-tailed).

${ }^{*}$ Correlation is significant at the 0.05 level (2-tailed).

population and is replicated in several international studies. A large Australian study on 449 cancer patients found that the meaning/peace component being more highly related to QOL than the faith component [47]. Similarly, in two longitudinal studies, Yanez et al. showed that meaning and peace act as a positive resource for cancer survivors, but faith may serve to facilitate or even hinder positive adjustment
[48]. In another study Canada et al. examined the 3-factor model for FACIT-SP-12 in two hundred and forty females previously diagnosed with cancer. They found that the peace factor was only correlated with mental health scores, meaning it was associated with both physical and mental health scores, and faith was negatively associated with mental health scores [49]. Edmondson et al. examined the role of religion in 
TABLE 3: Association of FACT-G and its subdomains with spiritual well-being, depression, and $\mathrm{HbA}_{1 \mathrm{c}}$.

\begin{tabular}{|c|c|c|c|c|c|c|c|c|c|c|}
\hline \multirow{3}{*}{ Predictors } & \multicolumn{10}{|c|}{ Dependent variables } \\
\hline & \multicolumn{2}{|c|}{ Physical well-being } & \multicolumn{2}{|c|}{ Social well-being } & \multicolumn{2}{|c|}{ Emotional well-being } & \multicolumn{2}{|c|}{ Functional well-being } & \multicolumn{2}{|c|}{ FACT-G } \\
\hline & $\beta$ & $P$ & $\beta$ & $P$ & $\beta$ & $P$ & $\beta$ & $P$ & $\beta$ & $P$ \\
\hline Meaning & 0.182 & 0.010 & 0.339 & 0.000 & 0.179 & 0.006 & 0.347 & 0.000 & 0.369 & 0.000 \\
\hline Peace & 0.195 & 0.007 & 0.217 & 0.005 & 0.321 & 0.000 & 0.383 & 0.000 & 0.253 & 0.001 \\
\hline Faith & 0.192 & 0.001 & 0.087 & 0.171 & 0.053 & 0.335 & 0.053 & 0.329 & 0.111 & 0.061 \\
\hline PHQ-2 & -0.374 & 0.000 & -0.075 & 0.311 & -0.344 & 0.000 & -0.046 & 0.466 & -0.111 & 0.107 \\
\hline $\mathrm{HbA}_{1 \mathrm{c}}$ & -00.049 & 00.419 & -0.006 & 0.923 & -0.012 & 0.824 & -0.040 & 0.475 & -0.052 & 0.387 \\
\hline$R^{2}$ & \multicolumn{2}{|c|}{0.374} & \multicolumn{2}{|c|}{0.270} & \multicolumn{2}{|c|}{0.454} & \multicolumn{2}{|c|}{0.461} & \multicolumn{2}{|c|}{0.368} \\
\hline$F$ & \multicolumn{2}{|c|}{23.56} & \multicolumn{2}{|c|}{14.61} & \multicolumn{2}{|c|}{32.76} & \multicolumn{2}{|c|}{33.70} & \multicolumn{2}{|c|}{22.92} \\
\hline
\end{tabular}

$\beta$ : standardized beta; $P$ : $P$ value; method: enter.

The bold $P$ values show the significant relationships among aspects of spirituality and QOL. Meaning and peace were significantly associated with all aspects of QOL.

providing a sense of meaning and concluded that "religious is beneficial to the degree to which it facilitates the creation and maintenance of meaning, coherence, and purpose. Conversely, if religious beliefs and practices fail to provide meaning or provide meaning that is destructive (i.e., God no longer cares for me), they are ineffectual or detrimental to well-being" [50]. However, many Islamic scholars believe that there is no distinction between religion and spiritual concepts, and spirituality is meaningless without religious thoughts and performances [51]. Coherent with this, Islamic clergy men are included in some hospitals in Iran to provide the religious care to patients. The main aspect of this model of care is to help patients to do the Islamic rituals appropriately, which is far away by the spiritual care model that includes an interdisciplinary management to address all dimensions of care, including the spiritual, religious, and existential as well as physical and psychological.

Diabetes destroys not only the physical well-being of the patients but also threatens the social, functional, and emotional well-being of the patients. This condition causes the patients to ask about themselves, their purpose, and their meaning in life. Victor Frankl in his famous book "Man's search for meaning" states "Human is not destroyed by suffering; he is destroyed by suffering without meaning" [52]. Meaning has been assessed in terms of the sense of purpose in life, productivity, and reason for living [29]. This sense of meaning helps the patients to cope with their disease, reframing their lives, having an optimistic look on life and a "fighting spirit" against their disease [53, 54]. Previous studies on diabetic patients indicated that higher spiritual well-being is associated with lower $\mathrm{HbA}_{1 \mathrm{c}}$ and better adjustment to disease [22]. The findings of this study reflects that the sense of inner peace and intrinsic strength may guard against negative feelings and probably result in maintaining higher self-care behaviors and thus, greater glycemic control in those with diabetes. This highlights the need for considering spiritual issues in caring of the diabetic patients [55].

In our study controlled diabetes group $\left(\mathrm{HbA}_{1 \mathrm{c}}\right.$ level $\left.\leq 7\right)$ has better QOL and spiritual well-being in comparison to uncontrolled group $\left(\mathrm{HbA}_{1 \mathrm{c}}\right.$ level > 7). This is in line with the results of other studies indicating significant association of spiritual well-being and diabetes control [22, 23, 43].
A qualitative study on 70 African American women with type 2 diabetes showed the influence of spirituality in selfmanagement of people with type 2 diabetes resulted in diabetes control [56].

In our studied population, individuals in the uncontrolled group had worse QOL. Diabetes can exert a negative impact on QOL [12]. Since diabetes is a chronic lifelong disease, patients with diabetes must deal with their disease all day. Medical therapy, diabetes complications, episodes of hypoglycemia, and fear of long term consequences may lead to reduced quality of life [57]. Furthermore, psychosocial toll of living with diabetes and psychiatric disorders such as depression were shown to be associated with poorer QOL [58].

Depression and diabetes are significantly connected to each other [59]. In this study, $63.5 \%$ of our studied population had depressive disorders. The prevalence of depression in our diabetic sample was higher than the range of $2 \%-9.5 \%$ in Iranian adults [60-62] as well as the rate of $8.3-28.8 \%$ of the diabetic patients in the United States [63]. However, the estimates of depression prevalence among individuals with diabetes appear to be higher in developing countries [64]. In a single point cross-sectional study done in India, depression was diagnosed in $43.34 \%$ [65]. In a study done in Pakistan, depression was found in $43.5 \%$ of patients with diabetes [66]. In another study from Iran, Khamseh et al. found major depression in $71.8 \%$ of a sample of 206 patients with type 1 and type 2 diabetes [67]. Other reports from Iran using different tools for depression showed high rates of depression in people with diabetes [68-70]. The higher coincidence of depression in these populations may be due to the lower socioeconomic status that is a known risk factor for depression [71]. Furthermore, the high prevalence of depression in our sample may be due to use of a screening tool which may detect psychological distress rather than clinical depression and so may increase rates of disorder [72]. The results of our study showed that depression is negatively associated with all aspects of quality of life and spiritual well-being. In the regression analysis, depression was a significant predictor of physical and emotional well-being. This coheres with the results of previous studies that showed a moderate, negative association of depressive symptoms on physica and mental health [73-75], indicating the importance 
of detecting and managing depressive symptoms in diabetes care.

Our study, while having much strength, involved some limitations that should be mentioned. Our findings cannot be generalized to the general population of the patients with diabetes because sicker and older people with type 2 diabetes did not respond to the survey. Participants were from two clinics populations, and there was no general population comparison group to compare. Also, it is important to be aware that FACIT-Sp is not a diabetes specific tool to assess the quality of life and spiritual well-being. In this study we treat the spiritual well-being as the predictor variable. However the developers of this instrument believe that "... under certain conditions, spiritual well-being may function as a process variable or even as a dependent or outcome variable." Furthermore we did not assess the religious coping pattern in our participants. More research, particularly longitudinal, is warranted to direct the causation between spiritual well-being, QOL, and depression in diabetic patients and to examine the feasibility of deriving a spiritual history in diabetes care.

Despite these limitations, the current study appears to be unique in that we assessed the QOL, and spiritual well-being and their association among diabetic patients in an Islamic context.

\section{Conclusion}

The results of this study showed poor QOL and spiritual well-being and high prevalence of depression in Iranian patients with type 2 diabetes compared to other studies' findings, especially Western studies. This indicates the need for psychosocial and spiritual support in caring for Iranian patients with diabetes.

\section{Conflict of Interests}

The authors declare that there is no conflict of interests regarding the publication of this paper.

\section{Acknowledgments}

The authors wish to acknowledge all the patients who so graciously agreed to participate in this study. Also, the authors are greatly thankful to Dr. Hoseini of the Parvin Diabetes Clinic, Mr. Teyfoori of the Isfahan Diabetes Charity Center, and all staff of these centers for their support throughout the project.

\section{References}

[1] J. E. Shaw, R. A. Sicree, and P. Z. Zimmet, "Global estimates of the prevalence of diabetes for 2010 and 2030," Diabetes Research and Clinical Practice, vol. 87, no. 1, pp. 4-14, 2010.

[2] G. Danaei, M. M. Finucane, Y. Lu et al., "National, regional, and global trends in fasting plasma glucose and diabetes prevalence since 1980: systematic analysis of health examination surveys and epidemiological studies with 370 country-years and 2.7 million participants," The Lancet, vol. 378, no. 9785, pp. 31-40, 2011.

[3] A. Esteghamati, M. M. Gouya, M. Abbasi et al., "Prevalence of diabetes and impaired fasting glucose in the adult population of Iran: National survey of risk factors for non-communicable diseases of Iran," Diabetes Care, vol. 31, no. 1, pp. 96-98, 2008.

[4] M. D. Llorente and V. Urrutia, "Diabetes, psychiatric disorders, and the metabolic effects of antipsychotic medications," Clinical Diabetes, vol. 24, no. 1, pp. 18-24, 2006.

[5] S. Ali, M. A. Stone, J. L. Peters, M. J. Davies, and K. Khunti, "The prevalence of co-morbid depression in adults with type 2 diabetes: a systematic review and meta-analysis," Diabetic Medicine, vol. 23, no. 11, pp. 1165-1173, 2006.

[6] C. Li, L. Barker, E. S. Ford, X. Zhang, T. W. Strine, and A. H. Mokdad, "Diabetes and anxiety in US adults: findings from the 2006 behavioral risk factor surveillance system," Diabetic Medicine, vol. 25, no. 7, pp. 878-881, 2008.

[7] C. Li, E. S. Ford, G. Zhao, L. S. Balluz, J. T. Berry, and A. H. Mokdad, "Undertreatment of mental health problems in adults with diagnosed diabetes and serious psychological distress: the behavioral risk factor surveillance system, 2007," Diabetes Care, vol. 33, no. 5, pp. 1061-1064, 2010.

[8] F. Pouwer, "Should we screen for emotional distress in type 2 diabetes mellitus?" Nature Reviews Endocrinology, vol. 5, no. 12, pp. 665-671, 2009.

[9] G. Rodin, "Quality of life in adults with insulin-dependent diabetes mellitus," Psychotherapy and Psychosomatics, vol. 54, no. 2-3, pp. 132-139, 1990.

[10] B. K. Haas, "A multidisciplinary concept analysis of quality of life," Western Journal of Nursing Research, vol. 21, no. 6, pp. 728742, 1999.

[11] M. A. Verdugo and R. L. Schalock, "Quality of life: from concept to future applications in the field of intellectual disabilities," Journal of Policy and Practice in Intellectual Disabilities, vol. 6, no. 1, pp. 62-64, 2009.

[12] R. R. Rubin and M. Peyrot, "Quality of life and diabetes," Diabetes/Metabolism Research and Reviews, vol. 15, no. 3, pp. 205-218, 1999.

[13] W. K. Redekop, M. A. Koopmanschap, R. P. Stolk, G. E. H. M. Rutten, B. H. R. Wolffenbuttel, and L. W. Niessen, "Healthrelated quality of life and treatment satisfaction in Dutch patients with type 2 diabetes," Diabetes Care, vol. 25, no. 3, pp. 458-463, 2002.

[14] V. Sparring, L. Nyström, R. Wahlström, P. M. Jonsson, J. Östman, and K. Burström, "Diabetes duration and healthrelated quality of life in individuals with onset of diabetes in the age group 15-34 years-a Swedish population-based study using EQ-5D," BMC Public Health, vol. 13, article 377, 2013.

[15] O. Solli, K. Stavem, and I. Kristiansen, "Health-related quality of life in diabetes: the associations of complications with EQ5D scores," Health and Quality of Life Outcomes, vol. 8, article $18,2010$.

[16] T. Borneman, B. Ferrell, and C. M. Puchalski, "Evaluation of the FICA tool for spiritual assessment," Journal of Pain and Symptom Management, vol. 40, no. 2, pp. 163-173, 2010.

[17] C. Puchalski, B. Ferrell, R. Virani et al., "Improving the quality of spiritual care as a dimension of palliative care: the report of the consensus conference," Journal of Palliative Medicine, vol. 12, no. 10, pp. 885-904, 2009.

[18] M. M. Rowe and R. G. Allen, "Spirituality as a means of coping with chronic illness," American Journal of Health Studies, vol. 19, pp. 62-66, 2003. 
[19] S. Cotton, C. M. Puchalski, S. N. Sherman et al., "Spirituality and religion in patients with HIV/AIDS," Journal of General Internal Medicine, vol. 24, no. 8, 994 pages, 2009.

[20] K. S. Johnson, J. A. Tulsky, J. C. Hays et al., "Which domains of spirituality are associated with anxiety and depression in patients with advanced illness?" Journal of General Internal Medicine, vol. 26, no. 7, pp. 751-758, 2011.

[21] R. Sawatzky, P. A. Ratner, and L. Chiu, "A meta-analysis of the relationship between spirituality and quality of life," Social Indicators Research, vol. 72, no. 2, pp. 153-188, 2005.

[22] N. Parsian and T. Dunning, "Spirituality and coping in young adults with diabetes: a cross-sectional study," European Diabetes Nursing, vol. 6, no. 3, pp. 100-104, 2009.

[23] R. L. Polzer and M. S. Miles, "Spirituality in African Americans with diabetes: self-management through a relationship with God," Qualitative Health Research, vol. 17, no. 2, pp. 176-188, 2007.

[24] K. Newlin, G. D. Melkus, R. Tappen, D. Chyun, and H. G. Koenig, "Relationships of religion and spirituality to glycemic control in black women with type 2 diabetes," Nursing Research, vol. 57, no. 5, pp. 331-339, 2008.

[25] M. H. Maslakpak, F. Ahmadi, and M. Anoosheh, "Spiritual beliefs and quality of life: a qualitative research about diabetic adolescent girls' perception," Koomesh, vol. 12, no. 2, pp. 144-151, 2010.

[26] S. Abdoli, T. Ashktorab, F. Ahmadi, S. Parvizy, and T. Dunning, "Religion, faith and the empowerment process: stories of Iranian people with diabetes," International Journal of Nursing Practice, vol. 17, no. 3, pp. 289-298, 2011.

[27] N. W. Scott, P. M. Fayers, N. K. Aaronson et al., "The relationship between overall quality of life and its subdimensions was influenced by culture: analysis of an international database," Journal of Clinical Epidemiology, vol. 61, no. 8, pp. 788-795, 2008.

[28] M. J. Brady, A. H. Peterman, G. Fitchett, M. Mo, and D. Cella, "A case for including spirituality in quality of life measurement in oncology," Psychooncology, vol. 8, no. 5, pp. 417-428, 1999.

[29] J. M. Bredle, J. M. Salsman, S. M. Debb, B. J. Arnold, and D. Cella, "Spiritual well-being as a component of health-related quality of life: the functional assessment of chronic illness therapy—spiritual well-being scale (FACIT-Sp)," Religions, vol. 2, pp. 77-94, 2011.

[30] D. F. Cella, D. S. Tulsky, G. Gray et al., "The functional assessment of cancer therapy scale: development and validation of the general measure," Journal of Clinical Oncology, vol. 11, no. 3, pp. 570-579, 1993.

[31] N. Jafari, A. Zamani, M. Lazenby, Z. Farajzadegan, H. Emami, and A. Loghmani, "Translation and validation of the Persian version of the functional assessment of chronic illness therapyspiritual well-being scale (FACIT-Sp) among Muslim Iranians in treatment for cancer," Palliative and Supportive Care, vol. 1, pp. 1-7, 2012.

[32] K. Kroenke, R. L. Spitzer, and J. B. W. Williams, “The patient health questionnaire-2: validity of a two-item depression screener," Medical Care, vol. 41, no. 11, pp. 1284-1292, 2003.

[33] B. Löwe, K. Kroenke, and K. Gräfe, "Detecting and monitoring depression with a two-item questionnaire (PHQ-2)," Journal of Psychosomatic Research, vol. 58, no. 2, pp. 163-171, 2005.

[34] H. F. Burr, "Evaluation of glycosylated hemoglobin in diabetic patients," Diabetes, vol. 30, no. 7, pp. 613-617, 1981.
[35] H. S. Whitford and I. N. Olver, "The multidimensionality of spiritual wellbeing: peace, meaning, and faith and their association with quality of life and coping in oncology," Psychooncology, vol. 21, no. 6, pp. 602-610, 2012.

[36] D. G. Kleinbaum, L. L. Kupper, and K. E. Muller, Applied Regression Analysis and Other Multivariable Methods, Duxbury Pr, 2007.

[37] K. Webster, D. Cella, and K. Yost, "The functional assessment of chronic illness therapy (FACIT) measurement system: properties, applications, and interpretation," Health and Quality of Life Outcomes, vol. 1, article 79, 2003.

[38] N. Jafari, A. Zamani, M. Lazenby, Z. Farajzadegan, H. Emami, and A. Loghmani, "Translation and validation of the Persian version of the functional assessment of chronic illness therapyspiritual well-being scale (FACIT-Sp) among Muslim Iranians in treatment for cancer," Palliative and Supportive Care, vol. 11, no. 1, pp. 29-35, 2013.

[39] M. Lazenby, J. Khatib, F. Al-Khair, and M. Neamat, "Psychometric properties of the functional assessment of chronic illness therapy-spiritual well-being (FACIT-Sp) in an Arabic-speaking, predominantly Muslim population," Psychooncology, vol. 22, no. 1, pp. 220-227, 2013.

[40] A. H. Peterman, G. Fitchett, M. J. Brady, L. Hernandez, and D. Cella, "Measuring spiritual well-being in people with cancer: the functional assessment of chronic illness therapy-spiritual well-being scale (FACIT-Sp)," Annals of Behavioral Medicine, vol. 24, no. 1, pp. 49-58, 2002.

[41] B. J. Zinnbauer, K. I. Pargament, B. Cole et al., "Religion and spirituality: unfuzzying the fuzzy," Journal for the Scientific Study of Religion, vol. 36, no. 4, pp. 549-564, 1997.

[42] C. M. Puchalski, A Time for Listening and Caring: Spirituality and the Care of the Chronically Ill and Dying, Oxford University Press, New York, NY, USA, 2006.

[43] N. Unantenne, N. Warren, R. Canaway, and L. Manderson, "The strength to cope: spirituality and faith in chronic disease," Journal of Religion and Health, pp. 1-15, 2011.

[44] C. J. W. Ehman, "Spirituality \& health: a select bibliography of medline-indexed articles published in," Palliative Medicine, vol. 6, no. 6, pp. 932-933, 2003.

[45] D. Baldacchino and P. Draper, "Spiritual coping strategies: a review of the nursing research literature," Journal of Advanced Nursing, vol. 34, no. 6, pp. 833-841, 2001.

[46] K. I. Pargament, B. W. Smith, H. G. Koenig, and L. Perez, "Patterns of positive and negative religious coping with major life stressors," Journal for the Scientific Study of Religion, vol. 37, no. 4, pp. 710-724, 1998.

[47] H. S. Whitford, I. N. Olver, and M. J. Peterson, "Spirituality as a core domain in the assessment of quality of life in oncology," Psychooncology, vol. 17, no. 11, pp. 1121-1128, 2008.

[48] B. Yanez, D. Edmondson, A. L. Stanton et al., "Facets of spirituality as predictors of adjustment to cancer: relative contributions of having faith and finding meaning," Journal of Consulting and Clinical Psychology, vol. 77, no. 4, pp. 730-741, 2009.

[49] A. L. Canada, P. E. Murphy, G. Fitchett, A. H. Peterman, and L. R. Schover, "A 3-factor model for the FACIT-Sp," Psychooncology, vol. 17, no. 9, pp. 908-916, 2008.

[50] D. Edmondson, C. L. Park, T. O. Blank, J. R. Fenster, and M. A. Mills, "Deconstructing spiritual well-being: existential wellbeing and HRQOL in cancer survivors," Psychooncology, vol. 17, no. 2, pp. 161-169, 2008. 
[51] G. H. Rassool, "The crescent and Islam: Healing, nursing and the spiritual dimension. Some considerations towards an understanding of the Islamic perspectives on caring," Journal of Advanced Nursing, vol. 32, no. 6, pp. 1476-1484, 2000.

[52] V. E. Frankl, Man's Search for Meaning, Washington Square, New York, NY, USA, Rev. edition, 1984.

[53] C. M. Puchalski, "Spirituality and health: the art of compassionate medicine," Hospital Physician, vol. 37, pp. 30-36, 2001.

[54] M. S. Yi, J. M. Mrus, T. J. Wade et al., "Religion, spirituality, and depressive symptoms in patients with HIV/AIDS," Journal of General Internal Medicine, vol. 21, no. 5, pp. S21-S27, 2006.

[55] C. P. Lynch, M. A. Hernandez-Tejada, J. L. Strom, and L. E. Egede, "Association between spirituality and depression in adults with type 2 diabetes," The Diabetes Educator, vol. 38, no. 3, pp. 427-435, 2012.

[56] C. D. Samuel-Hodge, S. W. Headen, A. H. Skelly et al., "Influences on day-to-day self-management of type 2 diabetes among African-American women: spirituality, the multi-caregiver role, and other social context factors," Diabetes Care, vol. 23, no. 7, pp. 928-933, 2000

[57] C. Fidler, T. Elmelund Christensen, and S. Gillard, "Hypoglycemia: an overview of fear of hypoglycemia, quality-of-life, and impact on costs," Journal of Medical Economics, vol. 14, no. 5, pp. 646-655, 2011.

[58] M. T. Schram, C. A. Baan, and F. Pouwer, "Depression and quality of life in patients with diabetes: a systematic review from the European depression in diabetes (EDID) research consortium," Current Diabetes Reviews, vol. 5, no. 2, pp. 112-119, 2009.

[59] A. Nouwen, K. Winkley, J. Twisk et al., "Type 2 diabetes mellitus as a risk factor for the onset of depression: a systematic review and meta-analysis," Diabetologia, vol. 53, no. 12, pp. 2480-2486, 2010.

[60] M. J. Modabernia, H. S. Tehrani, M. Fallahi, M. Shirazi, and A. H. Modabbernia, "Prevalence of depressive disorders in Rasht, Iran: a community based study," Clinical Practice and Epidemiology in Mental Health, vol. 4, article 20, 2008.

[61] M. R. Mohammadi, H. Ghanizadeh, A. Noorbala, H. Davidian, A. Malek, and H. R. Naghavi, "Prevalence of mood disorders in Iran," Iranian Journal of Psychiatry, vol. 1, pp. 59-64, 2006.

[62] M.-R. Mohammadi, H. Davidian, A. A. Noorbala et al., "An epidemiological survey of psychiatric disorders in Iran," Clinical Practice and Epidemiology in Mental Health, vol. 1, article 16, 2005.

[63] C. Li, E. S. Ford, T. W. Strine, and A. H. Mokdad, "Prevalence of depression among U.S. adults with diabetes: findings from the 2006 behavioral risk factor surveillance system," Diabetes Care, vol. 31, no. 1, pp. 105-107, 2008.

[64] L. E. Egede and C. Ellis, "Diabetes and depression: global perspectives," Diabetes Research and Clinical Practice, vol. 87, no. 3, pp. 302-312, 2010.

[65] S. Bajaj, S. K. Agarwal, A. Varma, and V. K. Singh, "Association of depression and its relation with complications in newly diagnosed type 2 diabetes," Indian Journal of Endocrinology and Metabolism, vol. 16, article 759, 2012.

[66] A. K. Khuwaja, S. Lalani, R. Dhanani, I. S. Azam, G. Rafique, and F. White, "Anxiety and depression among outpatients with type 2 diabetes: a multi-centre study of prevalence and associated factors," Diabetology and Metabolic Syndrome, vol. 2, no. 1, article 72, 2010.
[67] M. E. Khamseh, H. R. Baradaran, and H. Rajabali, "Depression and diabetes in Iranian patients: a comparative study," International Journal of Psychiatry in Medicine, vol. 37, no. 1, pp. 81-86, 2007.

[68] B. Larijani, M. K. S. Bayat, M. K. Gorgani, F. Bandarian, S. Akhondzadeh, and S. A. Sadjadi, "Association between depression and diabetes," German Journal of Psychiatry, vol. 7, no. 4, pp. 62-65, 2004.

[69] A. N. Safa, B. Larijani, B. Shariati, H. Amini, and A. Rezagholizadeh, "Depression, quality of life and glycemic control in patients with diabetes," Iranian Journal of Diabetes and Lipid Disorders, vol. 7, no. 2, pp. 195-204, 2007.

[70] W. Katon, M. von Korff, P. Ciechanowski et al., "Behavioral and clinical factors associated with depression among individuals with diabetes," Diabetes Care, vol. 27, no. 4, pp. 914-920, 2004.

[71] W. W. Eaton, "Epidemiologic evidence for the relation between socioeconomic status and depression, obesity, and diabetes," Journal of Psychosomatic Research, vol. 53, no. 4, pp. 891-895, 2002.

[72] A. K. Ibrahim, S. J. Kelly, C. E. Adams, and C. Glazebrook, "A systematic review of studies of depression prevalence in university students," Journal of Psychiatric Research, vol. 47, no. 3, pp. 391-400, 2013.

[73] N. Webinar, Q. E. Roundtable, and B. W. Part, "Minor depression and health status among US adults with diabetes mellituspage 3," The American Journal of Managed Care, vol. 13, pp. 6572, 2007.

[74] J. A. Hänninen, J. K. Takala, and S. M. Keinänen-Kiukaanniemi, "Depression in subjects with type 2 diabetes: predictive factors and relation to quality of life," Diabetes Care, vol. 22, no. 6, pp. 997-998, 1999.

[75] M. D. Pawaskar, R. T. Anderson, and R. Balkrishnan, "Selfreported predictors of depressive symptomatology in an elderly population with type 2 diabetes mellitus: a prospective cohort study," Health and Quality of Life Outcomes, vol. 5, article 50, 2007. 


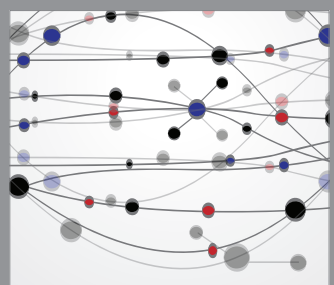

The Scientific World Journal
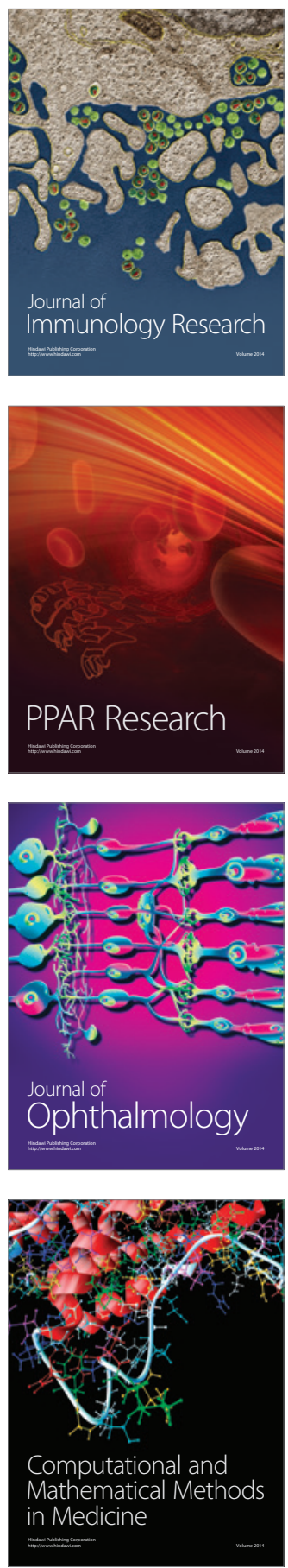

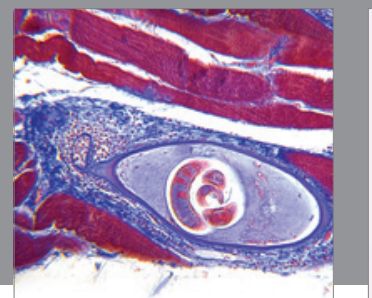

Gastroenterology

Research and Practice
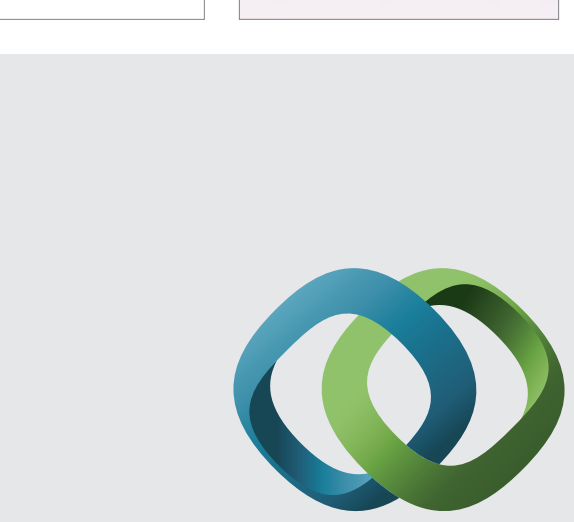

\section{Hindawi}

Submit your manuscripts at

http://www.hindawi.com
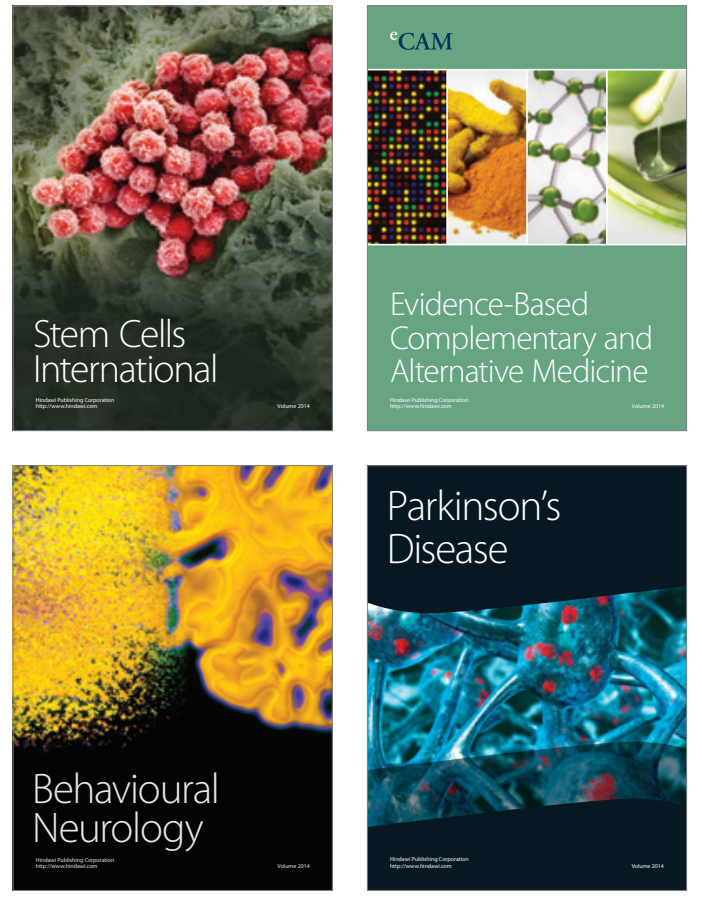
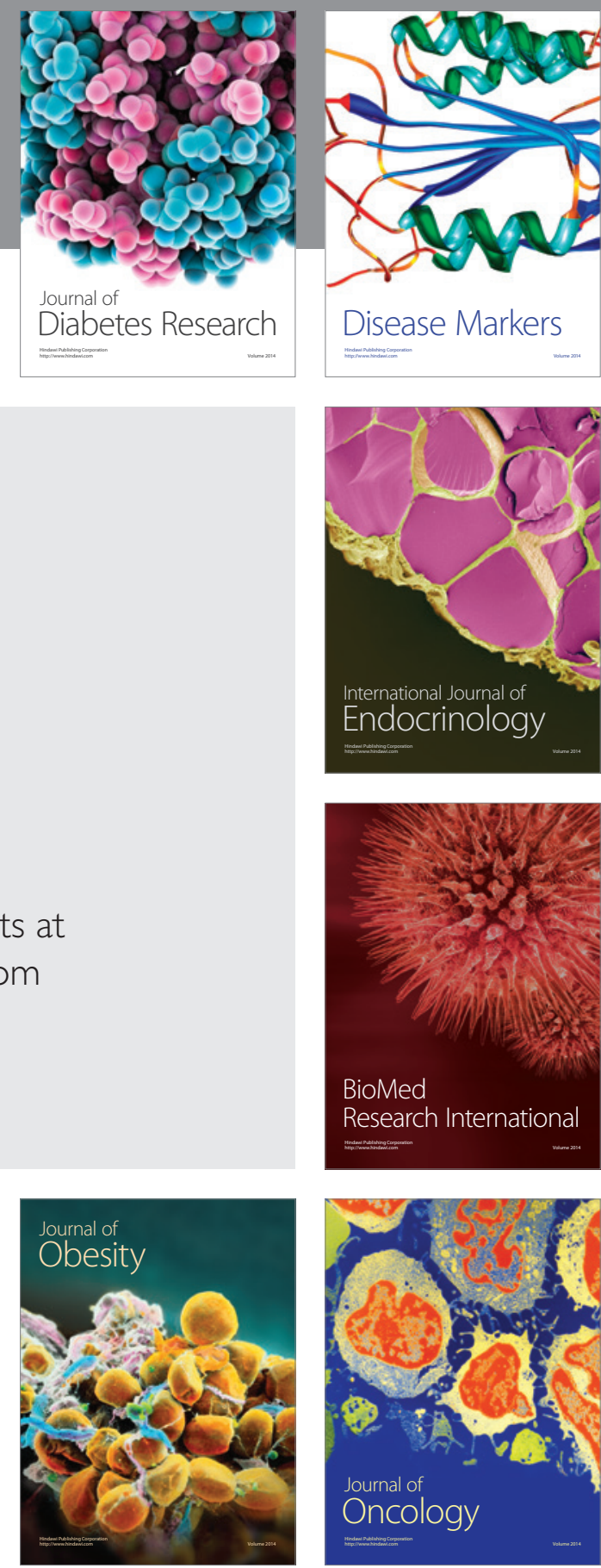

Disease Markers
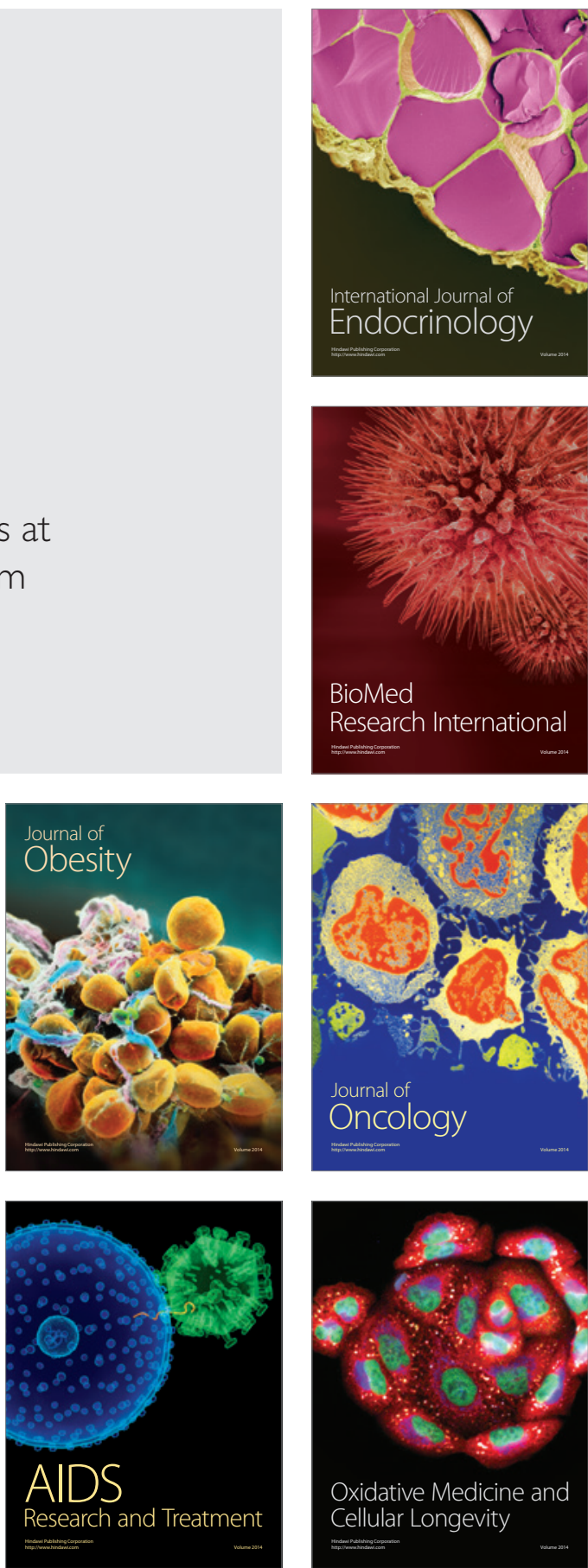